\title{
AMPLIFICAÇÃO CRUZADA DE PRIMERS SSR DE CAFEEIRO EM GENÓTIPOS DE ANTÚRIO
}

\author{
Edilson Marques Junior ${ }^{1}$ \\ Franciele Barros de Souza Sobreira ${ }^{2}$ \\ Carla Cristina Gonçalves Rosado 3 \\ José Dias de Souza Neto ${ }^{4}$ \\ Taís Cristina Bastos Soares ${ }^{5}$
}

Resumo: Anthurium andraeanum Lindl. é uma espécie florística, de grande importância na diversificação da agricultura tropical. É a segunda flor tropical no mercado mundial, no entanto há uma dificuldade para a delimitação taxonômica do gênero. Estudos com marcadores moleculares eliminam algumas dificuldades encontradas quando se trabalha com marcadores morfológicos, e dentre as várias classes de marcadores moleculares, os marcadores microssatélites (SSR) apresentam interessantes características para a distinção e classificação de indivíduos. Porém, o desenvolvimento de primers específicos para uma espécie requer um longo e oneroso trabalho. Até o momento não existem estudos moleculares de sequenciamento do genoma de antúrios, impossibilitando o desenvolvimento de marcadores moleculares para a espécie $A$. andraeanum, como o SSR. Considerando que os SSRs encontrados em determinadas espécies podem ser transferidos para espécies correlatas, neste trabalho foram testados 20 primers SSRs desenvolvidos para o cafeeiro em 16 genótipos de antúrio. Dos 20 primers testados, dois apresentaram amplificação para a espécie $A$. andraeanum, o que corresponde a $10 \%$ de taxa de transferência.

Palavras-chave: Anthurium andraeanum; Marcadores moleculares; Microssatélites; Transposição.

\footnotetext{
${ }^{1}$ Universidade Federal do Espírito Santo, Brasil. E-mail: edilsonmarquesjr@hotmail.com.

2 Universidade Federal do Espírito Santo, Brasil. E-mail: francielesouzza@gmail.com.

3 Universidade Federal do Espírito Santo, Brasil. E-mail: carlagrosado@yahoo.com.br.

${ }^{4}$ Setor de Biologia/Instituto Federal do Espírito Santo, Brasil. E-mail: jose.neto@ifes.edu.br.

5 Universidade Federal do Espírito Santo, Brasil. E-mail: tcbsoares@yahoo.com.br.
} 